\title{
Lectin, galactoside-binding, soluble, 3 rs4652 A/C gene variation and the risk for rheumatoid arthritis
}

\author{
MAHDI ATABAKI $^{1}$, MOHAMMAD HASHEMI ${ }^{2}$, HAMID DANESHVAR $^{3}$ and EBRAHIM ALIJANI ${ }^{1}$ \\ ${ }^{1}$ Clinical Immunology Research Center; ${ }^{2}$ Cellular and Molecular Research Center, \\ Zahedan University of Medical Sciences, Zahedan, Sistan and Baluchestan 98167-43181; \\ ${ }^{3}$ Department of Immunology, Kerman University of Medical Sciences, Kerman, Kerman 76169-14115, Iran
}

Received October 19, 2016; Accepted December 28, 2016

DOI: $10.3892 /$ br.2017.838

\begin{abstract}
Rheumatoid arthritis (RA) is a complex genetic disease. The lectin, galactoside-binding, soluble, 3 (LGALS3) gene, encodes a member of the galectin family of carbohydrate binding proteins, and is one of the best examples of a non-human leukocyte antigen gene associated with a risk for RA in various populations. In the current study, the association between LGALS3 rs4652 gene polymorphism and RA was examined. This case-control study was performed on the 120 patients with RA and 120 healthy subjects. Genomic DNA was extracted from whole blood, and gene polymorphism was tested using a tetra-primer amplification refractory mutation system-polymerase chain reaction. The results demonstrated that LGALS3 rs4652 AC genotype increased the risk of RA $(\mathrm{OR}=11.622,95 \% \mathrm{CI}=4.473-28.656 ; \mathrm{P}=0.001)$ when compared with the AA genotype. However, the CC genotype and the $\mathrm{C}$ allele were not associated with RA. These findings indicated an association between LGALS3 rs4652 variation and the risk of RA in a sample of Iranian individuals. Further studies with larger sample sizes and populations of different ethnicities are required to validate our findings.
\end{abstract}

\section{Introduction}

Autoimmune diseases are a clinically diverse group of complex diseases that include rheumatoid arthritis (RA), juvenile idiopathic arthritis, type 1 diabetes mellitus, multiple sclerosis, systemic lupus erythematosus, psoriasis and psoriatic arthritis. These diseases affect $4 \%$ of the global population (1) and common treatments include administration of non-steroidal

Correspondence to: Mr. Mahdi Atabaki, Clinical Immunology Research Center, Zahedan University of Medical Sciences, Daneshgah Street, Zahedan, Sistan and Baluchestan 98167-43181, Iran

E-mail: atabaki80@gmail.com

Key words: rheumatoid arthritis, polymorphism, lectin, galactoside-binding, soluble, 3 anti-inflammatory drugs, such as aspirin, corticosteroid drugs, methotrexate and anti-rheumatic drugs, including gold compounds.

RA is a systemic chronic immuno-inflammatory disease of unclear etiology involving progressive and destructive polyarthritis in association with serological evidence of auto-reactivity leading to persistent and progressive synovitis (2). Although the exact etiology of RA remains unknown, the interaction of immunological, genetic, infectious agent, environmental and hormonal factors has been demonstrated to contribute to its pathogenesis (3). Circulating antibodies, particularly the rheumatoid factor and anti-citrullinated protein antibody (ACPA), are important in the pathogenesis of RA (4). Synovial fibroblasts, macrophages, natural killer cells, $\mathrm{T} \mathrm{CD}^{+}$and $\mathrm{T} \mathrm{CD} 4^{+}$lymphocytes, B lymphocytes and plasma cells actively contribute to the inflamed synovium (4).

However, genetic risk factors do not fully justify the occurrence rate of RA; therefore, the role of environmental factors must also be considered. Environmental factors, such as weather, endemic microbes, lifestyle and diet are significantly associated with RA. For example, smoking, by individuals who express one of the predisposing alleles of RA, has been recognized as a risk factor for RA and contributes to the generation of ACPA (5).

Genetic studies are useful for determining predictive factors for diagnosing patients, and numerous studies regarding the genetics of RA have been performed (6-8). It is assumed that genetic factors account for $60 \%$ of the cause of RA susceptibility. The human leukocyte antigen (HLA)-DR4 allele associated with major histocompatibility complex (MHC) class II and other relevant alleles were recognized as the major genetic risk factors in the occurrence of RA. Recent studies have revealed that there is a very close association between MHC and the presence of ACPA. In certain Korean populations, which are HLA-DRB1-0405 or HLA-DRB1-0901 heterozygotes, the risk of RA susceptibility was found to be particularly high (4). However, HLA locus contributes to $30-50 \%$ of the genetic component of RA susceptibility (4).

The lectin, galactoside-binding, soluble, 3 (LGALS3) gene is located on chromosome 14 (14q22.3) and encodes galectin-3 protein. Galectins are lectins binding $\beta$-galactoside that have at least one of the carbohydrate recognition domains (CRDs) in their own structure. Approximately 15 members of this 
group have been identified in mammals (9). Galectin-3, a unique member of the galectins family, which has a CRD to identify the carbohydrate in its $\mathrm{C}$-terminal, and the $\mathrm{N}$-terminal domain, which is required for secretion (10). Galectin-3 has been identified in cells, such as activated macrophages (11), fibroblasts (12), dendritic cells (13), eosinophils (14), mast cells $(15)$ and osteoblasts $(11,16)$. Galectin-3 within the cell is important for regulation of post transcription of mRNA in the nucleus (17), cell growth (18) and protecting cells from apoptosis via Fas and tumor necrosis factor (TNF) $(19,20)$. Additionally, galectin-3 contributes to phagocytosis by macrophages (21), and galectin-3 deficient macrophages are incapable of phagocytosis of IgG-coated red blood cells and apoptotic cells (21). In a previous study, galectin-3 was introduced as an opsonin, which facilitates the clearance of apoptotic neutrophils (21). In addition, the role of galectin-3 in the morphogenesis and angiogenesis of endothelial cells has been demonstrated (22).

There are various single nucleotide polymorphisms in LGALS3 that affect its gene expression. For example, LGALS3 rs4644 $\mathrm{C}$ allele has recently been demonstrated to be associated with the risk of RA in a population from Taiwan (23). Thus, due to the role of the LGALS3 gene in the pathogenesis of various types of autoimmune disease, including RA, it presents as a suitable candidate for genetic studies. Therefore, the present study aimed to evaluate the possible association between LGALS3 rs4652 A/C genetic variation and the risk of RA in an Iranian population.

\section{Materials and methods}

Subjects. The present case-control study was performed on 120 patients (104 female, 16 male) with RA (mean age, 44.6 \pm 12.9 years) who fulfilled the American College of Rheumatology (ACR) criteria for RA (24). All the subjects were patients of the Rheumatology Clinic at Zahedan University of Medical Sciences (Zahedan, Iran) (25-27). The control group consisted of 120 healthy individual (76 females, 44 male; mean age, $43.2 \pm 10.3$ years) who were not related to the RA patients. The Ethics Committee of Zahedan University of Medical Sciences approved the project, and informed consent was obtained from all patients and healthy individuals. Blood samples $(3 \mathrm{ml})$ from patients and healthy control subjects were collected in EDTA-containing tubes. The characteristics of the subjects participating in the study are presented in Table I.

DNA extraction and polymerase chain reaction (PCR). Genomic DNA was extracted from the peripheral blood samples that had been collected into tubes containing EDTA, as described previously (25). The LGALS3 polymorphism was determined by a tetra-primer amplification refractory mutation system-PCR (tetra-ARMS PCR). Two external primers (forward outer, 5'-GGCTTATCCTGGACAGGC ACCTC-3' and reverse outer, 5'-TTTTTGACTCTACCAA CATACACCCAT-3') as common primer for control of PCR reaction and the two internal primers (forward inner, 5'-CATCTTCTGGACAGCCAAGTGTCA-3' specific for A allele and reverse inner, 5'-AGTGGCAGGGTAGGCTCC AGG-3' specific for $\mathrm{C}$ allele) were designed and used. Product sizes were $203 \mathrm{bp}$ for the $\mathrm{A}$ allele, $157 \mathrm{bp}$ for the $\mathrm{C}$ allele and
Table I. Demographic and biochemical characteristics of subjects from the current study.

\begin{tabular}{lcc}
\hline Characteristic & $\begin{array}{c}\text { Rheumatoid } \\
\text { arthritis patients } \\
(\mathrm{n}=120)\end{array}$ & $\begin{array}{c}\text { Control } \\
\text { subjects } \\
(\mathrm{n}=120)\end{array}$ \\
\hline Gender (female/male) & $104 / 16$ & $76 / 44$ \\
Age (years) & $44.6 \pm 12.9$ & $43.2 \pm 10.3$ \\
Disease duration (years) & $6.05 \pm 5.85$ & - \\
Rheumatoid factor & 89.2 & - \\
positivity (\%) & & - \\
Family history (\%) & 83.5 & - \\
CRP positivity (\%) & 91.7 & - \\
Anti-CCP positivity (\%) & 68.3 & \\
\hline
\end{tabular}

CRP, C-reactive protein; $\mathrm{CCP}$, cyclic citrullinated protein.

314 bp for the control outer band. The PCR was conducted using a commercially available PCR premix (AccuPower PCR PreMix; Bioneer Corporation, Daejeon, Korea) according to the manufacturer's instructions. Template DNA $(1 \mu \mathrm{l} ; \sim 100 \mathrm{ng} / \mu \mathrm{l}), 0.6 \mu \mathrm{l}$ of each inner forward and reverse primer $(10 \mu \mathrm{M})$ and $1.5 \mu 1$ of each outer forward and reverse primer $(12 \mu \mathrm{M})$ and $14.8 \mu \mathrm{l}$ DNase-free water were added into a $0.2-\mathrm{ml}$ PCR tube containing the AccuPower PCR PreMix. PCR cycling condition for LGALS3 were as follows: $95^{\circ} \mathrm{C}$ for $5 \mathrm{~min}$ followed by 30 cycles of $30 \mathrm{sec}$ at $95^{\circ} \mathrm{C}, 40 \mathrm{sec}$ at $67^{\circ} \mathrm{C}$, and $30 \mathrm{sec}$ at $72^{\circ} \mathrm{C}$, with a final step at $72^{\circ} \mathrm{C}$ for 10 min. PCR products were visualized on $2 \%$ agarose gel containing $0.5 \mu / \mathrm{ml}$ ethidium bromide, and images were obtained (Fig. 1). To ensure the tetra-ARMS-PCR genotyping quality, random samples were sequenced. The genotypes determined by PCR were concordant with those determined by sequencing (Fig. 2).

Statistical analysis. Statistical analysis was performed using SPSS version 18 software for windows (SPSS, Inc., Chicago, IL, USA). The possible associations between the LGALS3 genotypes with RA were assessed by computing the odds ratio (OR) and 95\% confidence intervals (95\% CI) from logistic regression analyses. $\mathrm{P}<0.05$ was considered to indicate a statistically significant difference.

\section{Results}

LGALS3 rs 4652 polymorphism data. The present study included 120 patients with RA and 120 healthy subjects. The genotypes and allele frequencies of LGALS3 rs4652 polymorphism are presented in Table II. A significant difference was identified between the groups regarding LGALS3 rs4652 polymorphism $(\mathrm{P}=0.001)$, suggesting that the $\mathrm{AC}$ genotype was a risk factor for $\mathrm{RA}(\mathrm{OR}=11.622,95 \% \mathrm{CI}=4.473-28.656$; $\mathrm{P}=0.001)$. However, the rs $4652 \mathrm{C}$ allele was not a risk factor for RA (OR=0.653, 95\% CI=0.069-6.198; $\mathrm{P}=0.710)$. In addition, the possible association between LGALS3 rs4652 and gender and ethnicity was examined. The current data indicated no 
Table II. Distribution of genotypes and allelic frequencies of LGALS3 rs4652 A/C between patients with rheumatoid arthritis (case; $\mathrm{n}=120$ ) and healthy subjects (control; $\mathrm{n}=120$ ).

\begin{tabular}{lcccccr}
\hline $\begin{array}{l}\text { LGALS3 } \\
\text { rs4652 }\end{array}$ & Case, $\mathrm{n}(\%)$ & Control, $\mathrm{n}(\%)$ & OR $(95 \% \mathrm{CI})$ & P-value & OR $(95 \% \text { CI })^{\mathrm{a}}$ & P-value \\
\hline $\mathrm{AA}$ & $6(5)$ & $42(35)$ & Ref. & Ref. & & \\
$\mathrm{AC}$ & $113(94.2)$ & $67(55.8)$ & $11.80(4.765-29.248)$ & 0.001 & $11.622(4.473-28.656)$ & 0.001 \\
$\mathrm{CC}$ & $1(0.8)$ & $11(9.2)$ & $0.636(0.069-5.851)$ & 0.690 & $0.653(0.069-6.198)$ & 0.710 \\
CC+AC & $114(95)$ & $78(65)$ & $10.231(4.149-25.229)$ & 0.001 & $9.840(3.909-24.771)$ & 0.001 \\
Alleles & & & & & \\
A (wild) & $125(52.1)$ & $151(62.9)$ & Ref. & & \\
C (mutant) & $115(47.9)$ & $89(37.1)$ & $1.560(1.084-2.247)$ & 0.104 & \\
\hline
\end{tabular}

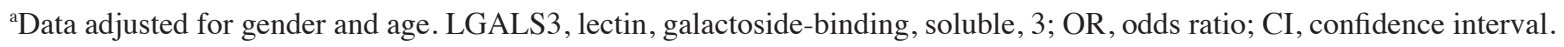

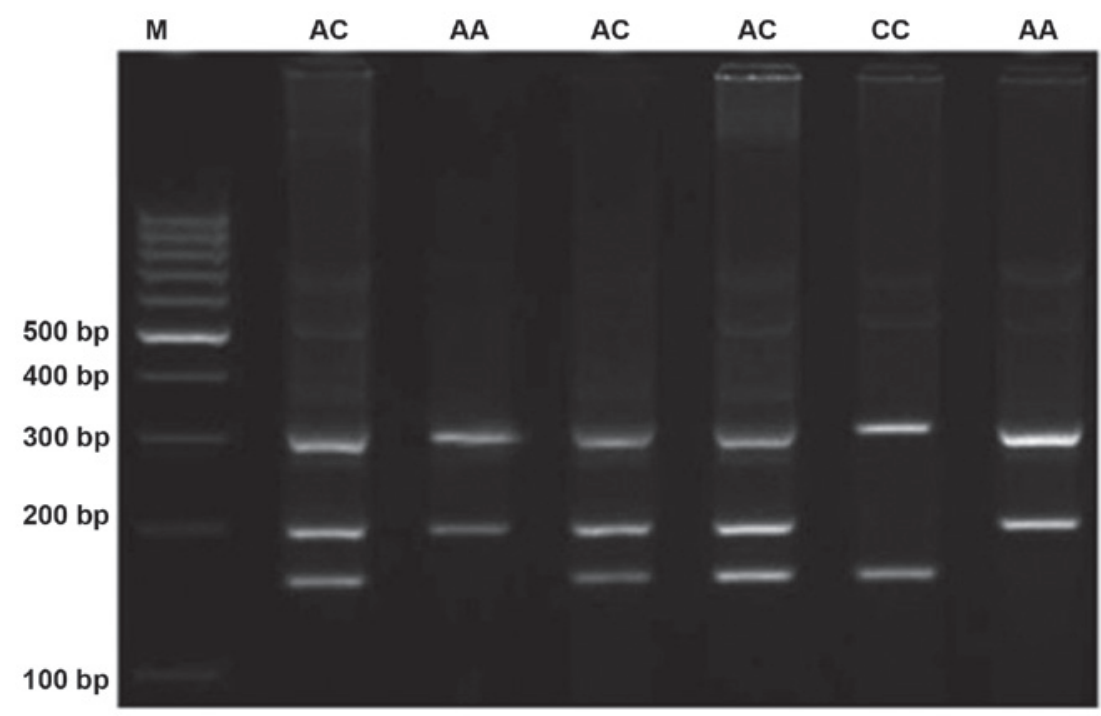

Figure 1. Electrophoresis pattern of tetra-primer amplification refractory mutation system-polymerase chain reaction for detection of LGALS3 polymorphism.

A

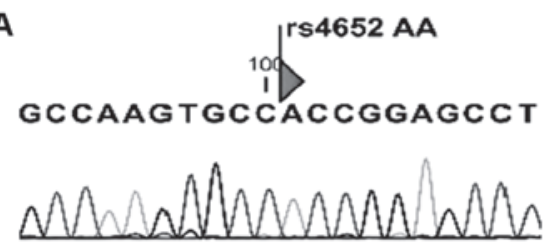

B

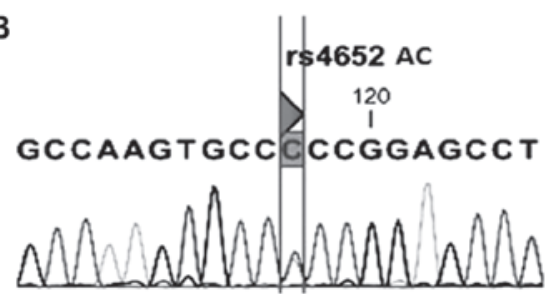

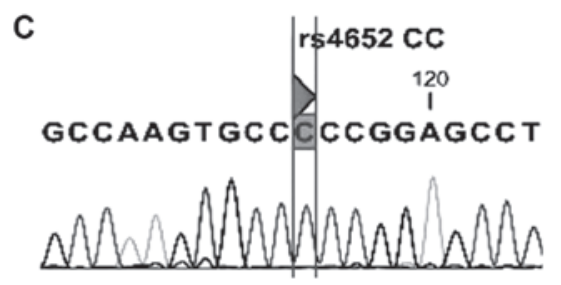

Figure 2. Sequencing results of LGALS3 genomic DNA. (A) Homozygous rs4652 AA, (B) heterozygous rs4652 AC and (C) homozygous rs4652 CC genotypes.

significant association between rs4652 A/C polymorphism with gender (male, $63.33 \%$ and female, $78.88 \% ; \mathrm{P}=0.50$ ) and ethnicity (Baluch, $73.38 \%$ and Fars, $76.72 \%$; $\mathrm{P}=0.77$ ).

\section{Discussion}

In the present study the possible association between LGALS3 
rs4652 (+292 A/C) gene polymorphism and the risk of RA was investigated. To the best of our knowledge this is the first study to investigate this polymorphism (LGALS3 rs4652) in an Iranian population. The results of the current study demonstrated that rs 4652 AC genotype significantly increased the risk of RA in the Iranian population that was evaluated.

RA is a chronic systemic disease, which is characterized by inflammation, alterations in the humoral and cellular immune responses, and synovial hyperplasia. Galectins are key in various pathologic conditions, including metastasis of tumor cells, autoimmune diseases and inflammation. The galectin-3 gene is composed of six exons and encodes a $32-k D a$ protein (28). Along with a number of surface receptors, galectin-3 activates lymphoid and myeloid cells, which results in interleukin (IL)-2 production in T lymphocytes (29) and IgE production in B lymphocytes (30). Furthermore, galectin-3 increases the production and release of free superoxide radicals in neutrophils and monocytes contributing to RA progression (31). Galectin-3 has been identified in the synovial tissue of patients with RA, and it is considered to be a positive regulator of proinflammatory chemokine and cytokine production (32). Increased expression levels of galectin-3 in the synovial tissue of RA patients promotes the production of proinflammatory chemokines, such as IL-6, granulocyte-macrophage colony-stimulating factor, TNF, $\mathrm{C}-\mathrm{X}-\mathrm{C}$ motif chemokine ligand $8, \mathrm{C}-\mathrm{C}$ motif chemokine ligand 2, CCL3 and CCL5 (33-35), all of which contribute to the inflammation, swelling, stiffness and joint destruction characteristics of RA. Therefore, blocking of galectin-3 is suggested as a potent strategy for the treatment of RA patients.

Previous studies have shown that galectin-3 performs different roles in various types of tissue and cell (11). In addition, galectin-3 has been associated with certain extracellular functions $(36,37)$. Galectin-3 within the cell is important for mRNA splicing in the nucleus (17), regulating cell growth (18), and protecting cells from death by Fas-induced apoptosis $(19,20)$ and TNF $(38)$. In addition, galectin-3 is known as an opsonin in clearing apoptotic neutrophils by macrophages (21). Furthermore, in rats with arthritis induced by collagen, increased expression levels of galectin-3 in peripheral monocytes have been reported (39).

In the current study, the results demonstrated that the frequencies of $\mathrm{AA}, \mathrm{AC}$, and $\mathrm{CC}$ were $5,94.2$ and $0.8 \%$ in $\mathrm{RA}$ patients, and 35, 55.8 and $9.2 \%$ in the control subjects. Our findings showed that the prevalence of the AC genotype in patients with RA (94.2\%) was significantly higher than in the control group (55.8\%), hence the rs4652 AC genotype was a risk factor for RA in the population investigated in the current study $(\mathrm{OR}=11.7)$. In contrast to our results, a study by Hu et al (23) indicated that the frequencies of LGALS3 rs4652 AA/AC/CC genotypes were 33.1, 47.7 and $19.2 \%$, respectively in RA patients, and 47.3,38.5 and $14.3 \%$ in the control subjects. The LGALS3 +292 C allele predisposed subjects to RA in a dominant genotype. Subjects that carried the LGALS3 +292C allele (+292AC or CC genotypes) were more susceptible to RA when compared with subjects with the +292AA genotype $(\mathrm{OR}=1.8$ and $95 \%$ confidence interval=1.2-2.8; $\mathrm{P}=0.009)$. In addition, the frequency of the $\mathrm{C}$ allele in the RA patients was identified to be $29(19.2 \%)$ and $26(14.3 \%)$ in the control group demonstrating a significant difference between groups $(\mathrm{P}=0.043)(23)$.

Hu et al (23) indicated that expression levels of cellular galectin-3 with the $\mathrm{CC}$ genotype in macrophages tended to be higher than those of the other genotypes. Furthermore, the authors showed that increased galectin-3 expression is associated with defective monocyte apoptosis in JIA. Such evidence highlights the important function of intracellular galectin-3 in the pathogenesis of RA (23).

In conclusion, the current study demonstrated that LGALS3 rs4652 AC was a risk factor for RA in a southeastern Iranian population and patients with this polymorphism may be susceptible to more severe clinical signs. Further studies with larger sample sizes are required to confirm these results.

\section{Acknowledgements}

The authors would like to thank the subjects who participated in the present study.

\section{References}

1. Hashemi M, Atabaki M, Daneshvar H, Zakeri Z and Eskandari-Nasab E: Association of PTPN22 rs2476601 and EGFR rs17337023 Gene polymorphisms and rheumatoid arthritis in Zahedan, Southeast Iran. Int J Immunogenet 40: 299-305, 2013.

2. Shalini P U, Debnath T, Jvs V, Kona LK, Kamaraju SR, Kancherla R and Chelluri LK: A study on FoxP3 and Tregs in paired samples of peripheral blood and synovium in rheumatoid arthritis. Cent Eur J Immunol 40: 431-436, 2015.

3. Bowes $\mathrm{J}$ and Barton A: Recent advances in the genetics of RA susceptibility. Rheumatology (Oxford) 47: 399-402, 2008.

4. Perricone C, Ceccarelli F and Valesini G: An overview on the genetic of rheumatoid arthritis: A never-ending story. Autoimmun Rev 10: 599-608, 2011.

5. Oliver JE and Silman AJ: Risk factors for the development of rheumatoid arthritis. Scand J Rheumatol 35: 169-174, 2006.

6. Amaya-Amaya J, Rojas-Villarraga A, Molano-Gonzalez N, Montoya-Sánchez L, Nath SK and Anaya JM: GDF15(MIC1) H6D Polymorphism Does Not Influence Cardiovascular Disease in a Latin American Population with Rheumatoid Arthritis. J Immunol Res 2015: 270763, 2015.

7. Huang CM, Chen SY, Huang PH and Tsai FJ: Effect of MPG gene rs2858056 polymorphism, copy number variation, and level of serum MPG protein on the risk for rheumatoid arthritis. PLoS One 10: e0120699, 2015.

8. Lee YH, Bae SC and Song GG: Meta-analysis of associations between functional prolactin -1149 G/T polymorphism and susceptibility to rheumatoid arthritis and systemic lupus erythematosus. Clin Rheumatol 34: 683-690, 2015.

9. Sato S, St-Pierre C, Bhaumik P and Nieminen J: Galectins in innate immunity: Dual functions of host soluble beta-galactoside-binding lectins as damage-associated molecular patterns (DAMPs) and as receptors for pathogen-associated molecular patterns (PAMPs). Immunol Rev 230: 172-187, 2009.

10. Menon RP and Hughes RC: Determinants in the N-terminal domains of galectin-3 for secretion by a novel pathway circumventing the endoplasmic reticulum-Golgi complex. Eur J Biochem 264: 569-576, 1999.

11. Liu FT, Patterson RJ and Wang JL: Intracellular functions of galectins. Biochim Biophys Acta 1572: 263-273, 2002.

12. Moutsatsos IK, Wade M, Schindler M and Wang JL: Endogenous lectins from cultured cells: Nuclear localization of carbohydrate-binding protein 35 in proliferating 3T3 fibroblasts. Proc Natl Acad Sci USA 84: 6452-6456, 1987.

13. Dietz AB, Bulur PA, Knutson GJ, Matasić R and Vuk-Pavlović S: Maturation of human monocyte-derived dendritic cells studied by microarray hybridization. Biochem Biophys Res Commun 275: $731-738,2000$.

14. Truong MJ, Gruart V, Liu FT, Prin L, Capron A and Capron M: IgE-binding molecules (Mac-2/epsilon $\mathrm{BP}$ ) expressed by human eosinophils. Implication in IgE-dependent eosinophil cytotoxicity. Eur J Immunol 23: 3230-3235, 1993. 
15. Craig SS, Krishnaswamy P, Irani AM, Kepley CL, Liu FT and Schwartz LB: Immunoelectron microscopic localization of galectin-3, an IgE binding protein, in human mast cells and basophils. Anat Rec 242: 211-219, 1995.

16. Colnot C, Sidhu SS, Poirier F and Balmain N: Cellular and subcellular distribution of galectin-3 in the epiphyseal cartilage and bone of fetal and neonatal mice. Cell Mol Biol (Noisy-le-grand) 45: 1191-1202, 1999.

17. Dagher SF, Wang JL and Patterson RJ: Identification of galectin-3 as a factor in pre-mRNA splicing. Proc Natl Acad Sci USA 92: 1213-1217, 1995

18. Sasaki S, Bao Q and Hughes RC: Galectin-3 modulates rat mesangial cell proliferation and matrix synthesis during experimental glomerulonephritis induced by anti-Thyl.1 antibodies. J Pathol 187: 481-489, 1999.

19. Fukumori T, Takenaka Y, Oka N, Yoshii T, Hogan V, Inohara H Kanayama HO, Kim HR and Raz A: Endogenous galectin-3 determines the routing of CD95 apoptotic signaling pathways. Cancer Res 64: 3376-3379, 2004

20. Hoyer KK, Pang M, Gui D, Shintaku IP, Kuwabara I, Liu FT, Said JW, Baum LG and Teitell MA: An anti-apoptotic role for galectin-3 in diffuse large B-cell lymphomas. Am J Pathol 164: 893-902, 2004

21. Karlsson A, Christenson K, Matlak M, Björstad A, Brown KL, Telemo E, Salomonsson E, Leffler $\mathrm{H}$ and Bylund J: Galectin-3 functions as an opsonin and enhances the macrophage clearance of apoptotic neutrophils. Glycobiology 19: 16-20, 2009.

22. Nangiamakker P, Thompson E, Hogan C, Ochieng J and Raz A: Induction of tumorigenicity by galectin-3 in a nontumorigenic human breast-carcinoma cell-line. Int J Oncol 7: 1079-1087, 1995.

23. Hu CY, Chang SK, Wu CS, Tsai WI and Hsu PN: Galectin-3 gene (LGALS3) $+292 \mathrm{C}$ allele is a genetic predisposition factor for rheumatoid arthritis in Taiwan. Clin Rheumatol 30: 1227-1233, 2011.

24. Arnett FC, Edworthy SM, Bloch DA, McShane DJ, Fries JF, Cooper NS, Healey LA, Kaplan SR, Liang MH, Luthra HS, et al: The American Rheumatism Association 1987 revised criteria for the classification of rheumatoid arthritis. Arthritis Rheum 31: 315-324, 1988.

25. Hashemi M, Moazeni-Roodi AK, Fazaeli A, Sandoughi M, Bardestani GR, Kordi-Tamandani DM and Ghavami S: Lack of association between paraoxonase-1 Q192R polymorphism and rheumatoid arthritis in southeast Iran. Genet Mol Res 9: 333-339, 2010.

26. Hashemi M, Moazeni-Roodi AK, Fazaeli A, Sandoughi M, Taheri M, Bardestani GR, Zakeri Z, Kordi-Tamandani DM and Ghavami S: The L55M polymorphism of paraoxonase-1 is a risk factor for rheumatoid arthritis. Genet Mol Res 9: 1735-1741, 2010.
27. Sandoughi M, Fazaeli A, Bardestani G and Hashemi M: Frequency of HLA-DRB1 alleles in rheumatoid arthritis patients in Zahedan, southeast Iran. Ann Saudi Med 31: 171-173, 2011.

28. Dumic J, Dabelic S and Flögel M: Galectin-3: An open-ended story. Biochim Biophys Acta 1760: 616-635, 2006.

29. Hsu DK, Hammes SR, Kuwabara I, Greene WC and Liu FT: Human T lymphotropic virus-I infection of human T lymphocy tes induces expression of the beta-galactoside-binding lectin, galectin-3. Am J Pathol 148: 1661-1670, 1996.

30. Kimata H: Enhancement of IgE production in B cells by neutrophils via galectin-3 in IgE-associated atopic eczema/dermatitis syndrome. Int Arch Allergy Immunol 128: 168-170, 2002

31. Yamaoka A, Kuwabara I, Frigeri LG and Liu FT: A human lectin, galectin-3 (epsilon bp/Mac-2), stimulates superoxide production by neutrophils. J Immunol 154: 3479-3487, 1995.

32. Kuwabara I and Liu FT: Galectin-3 promotes adhesion of human neutrophils to laminin. J Immunol 156: 3939-3944, 1996.

33. Filer A, Bik M, Parsonage GN, Fitton J, Trebilcock E, Howlett K, Cook M, Raza K, Simmons DL, Thomas AM, et al: Galectin 3 induces a distinctive pattern of cytokine and chemokine production in rheumatoid synovial fibroblasts via selective signaling pathways. Arthritis Rheum 60: 1604-1614, 2009.

34. Gao P, Simpson JL, Zhang J and Gibson PG: Galectin-3: Its role in asthma and potential as an anti-inflammatory target. Respir Res 14: 136, 2013.

35. Hu Y, Yéléhé-Okouma M, Ea HK, Jouzeau JY and Reboul P: Galectin-3: A key player in arthritis. Joint Bone Spine: May 26, 2016 (Epub ahead of print).

36. Krześlak A and Lipińska A: Galectin-3 as a multifunctional protein. Cell Mol Biol Lett 9: 305-328, 2004.

37. Ochieng J, Furtak V and Lukyanov P: Extracellular functions of galectin-3. Glycoconj J 19: 527-535, 2004.

38. Matarrese P, Tinari N, Semeraro ML, Natoli C, Iacobelli S and Malorni W: Galectin-3 overexpression protects from cell damage and death by influencing mitochondrial homeostasis. FEBS Lett 473: 311-315, 2000

39. Shou J, Bull CM, Li L, Qian HR, Wei T, Luo S, Perkins D, Solenberg PJ, Tan SL, Chen XY, et al: Identification of blood biomarkers of rheumatoid arthritis by transcript profiling of peripheral blood mononuclear cells from the rat collagen-induced arthritis model. Arthritis Res Ther 8: R28, 2006. 